Canadian

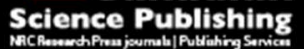

Canadian Journal of Civil Engineering Revue canadienne de génie civil

\title{
A Comprehensive collapse fragility assessment of moment resisting steel frames considering various sources of uncertainties
}

\begin{tabular}{|r|l|}
\hline Journal: & Canadian Journal of Civil Engineering \\
\hline Manuscript ID & cjce-2013-0491.R2 \\
\hline Manuscript Type: & Article \\
\hline Date Submitted by the Author: & $28-J u l-2015$ \\
\hline Complete List of Authors: & $\begin{array}{l}\text { Beheshti-Aval, Seyed Bahram; KNT University of Technology, civil } \\
\text { engineering } \\
\text { Khojastehfar, Ehsan; KNT University of Technology, civil engineering } \\
\text { Noori, Mohammad; Cal Poly, mechanical engineering; Research Affiliations- } \\
\text { International Institute for Urban Systems Engineering, Southeast } \\
\text { University } \\
\text { Zolfaghari, M.R.; K.N.Toosi University of Technology, Civil Engineering } \\
\text { Faculty }\end{array}$ \\
\hline Keyword: & $\begin{array}{l}\text { reliability analyses < Struct.Eng. \& Constr.Mate, uncertainty sources, } \\
\text { Collapse fragility curves, fuzzy inference system, response surface method }\end{array}$ \\
\hline
\end{tabular}




\title{
A Comprehensive collapse fragility assessment of moment resisting steel frames considering various sources of uncertainties
}

\author{
S.B. Beheshti-Aval ${ }^{\mathrm{a}}$, E. Khojastehfar ${ }^{\mathrm{b}}$, M. Noori ${ }^{\mathrm{c}}$, M.R. Zolfaghari ${ }^{\mathrm{a}}$ \\ a, Associate Professor, Civil Engineering Faculty, K.N. Toosi University of Technology, Tehran, Iran \\ ${ }^{b}$ PhD Candidate student, Civil Engineering Faculty, K.N. Toosi University of Technology, Tehran, Iran \\ ${ }^{c}$ Corresponding author, Professor, California Polytechnic State University, USA, and Affiliated with International \\ Institute for Urban Systems Engineering, Southeast University, China \\ Tel: 805-756-5581., Email: mnoori@outlook.com
}




\section{Abstract}

Different sources of uncertainties contribute to the collapse and safety assessment of structures. In this paper, impact of construction quality (CQ) is considered in developing analytical collapse fragility curves for moment resisting steel frames. Furthermore, the interaction of this source of uncertainty with epistemic uncertainty inherent in modeling parameters, due to lack of knowledge and inaccuracy of predictor equations, is investigated. Beam strength (BS), column strength (CS), beam ductility (BD) and column ductility (CD) meta-variables are defined as modeling parameters which are being suffered by informal uncertainty. Quadratic equations for the mean and the standard deviation of collapse fragility curves are derived by utilizing response surfaces, which are interpolated to analytically-derived values considering realizations for modeling variables and for various levels of construction quality. To the best of the authors' knowledge, interaction of modeling and CQ uncertainty in analytical collapse fragility curve hasnot been considered in previous investigations. A fuzzy rule-based method is applied to employ the effects of uncertainty due to CQ. Using Monte Carlo simulation for the modeling variables and the construction quality index, and subsequently computing response surface coefficients via a fuzzy inference system, and finally deriving collapse fragility curve parameters through response surfaces, result in collapse fragility curves of structures. In developing these curves, different sources of uncertainties are involved, ranging from lexical to informal and stochastic types. It is concluded that neglecting the effects of these sources leads to the underestimation of collapse fragility probability. This shows the importance of considering modeling and construction quality uncertainty effects on collapse fragility curves. It is shown that for a sample moment resisting steel frame collapse probability is increased $53 \%$ and $60 \%$ for $10 \%$ and $2 \%$ probability 
of exceedance in 50 years seismic hazard levels, respectively, while interaction of CQ and modeling uncertainties are considered in comparison with neglecting them. Otherwise, if only modeling uncertainty is involved, this increment is evaluated at $42 \%$ and $16 \%$, respectively for the aforementioned probabilities of exceedance.

Keywords: Collapse fragility curves, uncertainty sources, Fuzzy inference system, moment resisting steel structures, incremental dynamic analysis, Response Surface Method

\section{Introduction}

Extensive economic losses, caused by recent earthquakes have resulted in an increased attention and research towards seismic evaluation of existing buildings, while various sources of uncertainties are involved (Armenia earthquake reconnaissance report .1989 , Bam earthquake report. 2003, Sanada et al. 2004). Probabilistic framework in Performance-Based Earthquake Engineering, proposed by Pacific Earthquake Engineering Research Center (PEER), aims to evaluate earthquake risk (decision variables (DVs)) in terms of economic losses, downtime and number of casualties in a consistent probabilistic manner to facilitate making reasonable decisions (Deierlein 2004, Deierlein et al. 2003). In this context, mean annual frequency of exceedance for earthquake risk (in terms of mentioned DVs) is evaluated by convolution of uncertainties due to earthquake ground motion, structural response and induced damage to the structures.

Structural damage induced by earthquake, represented through probabilistic fragility curves, is one of the main components in PEER formulation. The most important damage state, considered in PEER methodology, is side-way collapse which is defined as the lateral instability of structures due to large drift ratio and p- $\Delta$ effects. This damage state is proved to be the main 
source of earthquake induced economic losses and human casualties (Armenia earthquake reconnaissance report .1989, Wang 2008, Moeindardari and Malekzadeh, et. al., 2014).

To achieve reasonable results for structural collapse capacity, analytical models which are capable of considering cyclic deterioration modes are required (Rahnama and Krawinkler 1993, Sivaselvan and Reinhorn 2002, Ibarra and Krawinkler 2005). These models consist of input parameters with inherent uncertainties, which have proven to have a considerable effect on collapse capacity of structures (Krawinkler et al. 2009). Furthermore, considerable earthquakeinduced damages are reported in under developed countries due to poor construction quality of structures, although these structures may have been designed based on earthquake-resistance codes. A good case study for these types of earthquake-induced damages is the destruction of government buildings in Bam, Iran, during December 26, 2003 Earthquake with a magnitude of Mw=6.5 (Fig.1) (Bam earthquake report. 2003, Sanada et al. 2004).

Uncertainty sources in collapse fragility curve may be categorized into aleatory, epistemic and lexical based on the related contributing factor (Möller et al. 2003). Aleatory uncertainty is mainly due to randomness nature of assumed problem and is irreducible. On the other hand, epistemic uncertainty initiates from lack of knowledge and inability of analytical models to mimic all aspects of structural behavior and may be reduced while more detailed models are applied. Characterization of these sources of uncertainties has been studied in the recent literature (e.g. Der Kiureghian and Ditlevsen 2009, Der Kiureghian 2008). The third source of uncertainty is due to subjective definition of parameters and hence, shows the lack of definite or sharp distinction. Various parameters in collapse assessment of structures suffer from these sources of uncertainty. 
Seismic performance of moment resisting steel structures is affected by several irregularities such as weak story, soft story, geometry, vertical discontinuities, construction quality, etc. (Rajeev and Tesfamariam 2012). Several investigations have considered the effects of each of these individual parameters (e.g. construction quality (Dimova and Negro 2006), soft story (Kappos and Panagopoulos 2010), building height (Erberik 2008) and building strength and ductility (Kazantzi et. al 2014)), as well as the interaction of these parameters (e.g. (Rajeev and Tesfamariam 2012)) on fragility curves. Furthermore, modeling the uncertainties is shown to have considerable impact on constructing collapse limit state fragility curves in comparison with those for other limit states, such as life safety and immediate occupancy (Liel et al. 2009). These factors indicate the importance of deriving collapse fragility curves involving modeling the uncertainty as well as considering various sources of irregularities.

Derivation of collapse fragility curves through incremental dynamic analysis (IDA) method, is assumed to be a consistent methodology to incorporate the effects of randomness uncertainty due to record-to-record variability and has been applied in various investigations (e.g. (Ibarra and Krawinkler 2005, Zareian and Krawinkler 2006)). In the work presented in this paper, in order to incorporate the variability of parameters suffering from lexical uncertainty, theory of fuzzy logic is employed (Kwakernaak 1978), which has been developed based on fuzzy sets (Zimmermann 2001). This theory has been used for structural analysis (Möller et al. 2000), safety assessment (Rajeev and Tesfamariam 2012) and risk analysis of structures (Tesfamariam and Saatcioglu 2010) to take into account effects of non-stochastic uncertainty (epistemic and lexical).

The key difference between the present study with simplified approaches (such as FEMA p695) is the applicability of the technique towards inclusion of construction quality uncertainty in collapse fragility curves. Considering simplified methods (such as FEMA p695), construction 
quality effect is incorporated by increasing the dispersion of the collapse fragility curve. The total dispersion of collapse fragility curve is calculated based on the square root of sum of squares (SRSS) of all variability sources (including material, modeling and construction quality). While in simplified methods, the dispersion due to construction quality is determined based on expert opinions. In the present study, the most efficient method (fuzzy inference method) that accounts for the inclusion of expert opinions uncertainty in median and dispersion of collapse fragility curve and in a quantitative manner, is presented.

\section{Theory of fuzzy rule base inferring}

Fuzzy logic, introduced by Zadeh, provides a tool to translate qualitative knowledge into numerical reasoning (Zadeh 1994). This logic, which is developed based on human reasoning and decision making encountering various types of uncertainty in real life, combines descriptive knowledge (linguistic variables) and numerical data through a fuzzy model and applies approximate reasoning algorithms to propagate uncertainties of each part throughout the decision. A fuzzy system consists of three main parts, entitled as fuzzification of input variables, fuzzy inference system (FIS), based on if-then rules, and defuzzification of outputs. Through constructing a fuzzy system, a map between fuzzy input variables and output variables, which may be regarded as fuzzy or numerical value, is constructed.

Numerical value of a linguistic variable (i.e. CQ in this study) can be represented by a fuzzy number. Fuzzy number is characterized by a membership function, which shows the degree of belongingness of numerical value to a descriptive set. Fuzzification of input variables consists of defining membership functions for each linguistic variable, which is entitled as granulation. 
Fuzzy inference system (FIS) consists of two parts. These are a fuzzy knowledge base and an inference mechanism. Fuzzy knowledge base is developed based on expert knowledge or inputoutput data, which are achieved analytically. The inference mechanism is the process to estimate the output of the system for a given input set. Furthermore, FIS may be updated by modifying the basic knowledge while achieving new information. The most popular FIS are Mamdani (Mamdani 1976) and Sugeno (Sugeno 1985). In the former; both antecedent and consequent of if-then rule are presented by linguistic variables. On the other hand, in the latter, the consequent part of if-then rule is defined by linear interpolation of input values. Since the aim of FIS in this study is to predict coefficients of response surfaces which are numerical variables, Sugeno inference system is applied. The if-then rule in Sugeno type of FIS is written as follows:

$R_{i}: I F \quad\left(X_{1}\right.$ is $\left.A_{1}\right) \quad A N D \quad\left(X_{2}\right.$ is $\left.A_{2}\right) \quad A N D \quad \ldots \quad T H E N \quad\left(Z_{i}=a X_{1}+b X_{2}+\ldots\right) \quad i=1, \ldots, N$

In which, $R_{i}$ is rule no. $i, X$ is the variable and $A$ is the fuzzy set corresponding to $X$. $a$ and $b$ are constants which are evaluated based on input data and $N$ is the number of rules.

Deffuzification of output, in Mamdani-type FIS, is the calculation of numeric output in applying output membership function, which can be done by various methods (e.g. center of mass, maximum, etc.). In Sugeno-type FIS, the final output is evaluated by the weighted average of all outputs (shown by equation (2)).

$$
\begin{aligned}
& \text { FinalOutput }=\frac{\sum_{i=1}^{N} w_{i} z_{i}}{\sum_{i=1}^{N} w_{i}} \\
& w_{i}=\operatorname{MIN}\left(F_{1}\left(X_{1 i}\right), F_{2}\left(X_{2 i}\right), \ldots\right)
\end{aligned}
$$


In which, $\mathrm{w}_{\mathrm{i}}$ is the firing strength of rule $\mathrm{i}$ and is defined by equation (3).

$F_{1}\left(X_{1}\right)$ and $F_{2}\left(X_{2}\right)$ are membership functions of variable $X_{1}$ and $X_{2}$, respectively.

\section{Research Methodology}

In this paper, the effects of lexical uncertainty in construction quality (CQ); informal or epistemic uncertainty in beam strength (BS), column strength (CS), beam ductility (BD) and column ductility (CD), and aleatory uncertainty from random nature of strong ground motion of earthquakes are considered to achieve collapse fragility curve of a typical steel moment resisting frame as the case study. Effect of aleatory uncertainty (i.e. strong ground motion variability) is considered through incremental dynamic analysis of a two dimensional sample frame of the structure when applying a set of 40 records proposed by (Medina and Krawinkler 2004). Modeling uncertainty effect is incorporated in response surface method, which has been applied in previous relevant literature (Liel et al. 2009). In the first step, numbers of realizations for modeling parameters (i.e. BS, CS, BD and CD) as inputs for IDA are considered. Then analytical response surfaces are interpolated through data points rendered from the results of IDA, which are a set of analytical equations through which mean and standard deviation of collapse are predicted. To include the effects of CQ, these response surfaces are derived for various levels of lexical variable, (i.e. $\mathrm{CQ}=\{\mathrm{GOOD}, \mathrm{AVERAGE}, \mathrm{POOR}\})$. To consider uncertainty of construction quality, response surface coefficients are predicted based on the fuzzy system, which is constructed based on Sugeno-type inference (Sugeno 1985). The final step of the proposed procedure is to simulate large number of values for $\mathrm{CQ}$ and modeling variables and inferring response surface coefficients through the fuzzy system, and lastly calculation of the collapse fragility curve through analytical response surfaces in which various sources of uncertainties are involved. Incorporated uncertainty sources and corresponding methodologies are shown in Fig.2. 


\section{Case Study}

A 3-storey 3-bay moment resisting steel structure (Fig.3a) is considered in order to evaluate the effects of various sources of uncertainties and their interaction on the collapse fragility curves. Typical story height is $3.2 \mathrm{~m}$. All floors are assumed to be rigid diaphragms based on commonly used floor systems in existing structures. Soil is considered to be type B. The gravity loads are assumed according to table (1). The building is designed according to UBC-97 (considering $\mathrm{R}=8.5)$ (UBC 1997). The seismic hazard condition is selected as Zone $4(\mathrm{Z}=0.40)$. The fundamental period of the frame is $1.075 \mathrm{~s}$. The nominal yield strength is $240 \mathrm{MPa}$, which is used for all members in the design. The section properties of members are shown on a twodimensional analytical model in Fig.3b. All beam sections are European Standard IPE 300 and all columns sections are box types. Exterior columns are BOX 180x180x16 and interior ones are BOX 200x200x 16.

Since the building is assumed to be symmetric in plan, consideration of a two-dimensional frame to evaluate seismic demand is feasible. Numerical modeling of the sample interior frame of a series of identical frames is implemented using OPENSEES finite element program (OpenSees 2002). Concentrated plasticity is assumed through assignment of nonlinear rotational springs in beam and column connections with modified Ibarra-Krawinkler moment-rotation model (Lignos 2008). This model is selected since it can incorporate different modes of hysteretic deterioration, which is a dominant factor in the estimation of side-way collapse capacity of structures. Sample frame and considered models of connections, as well as a panel zone model, are shown in Fig. $3 \mathrm{~b}$. P-Delta effects are incorporated in the model by applying the gravity load on the main frame and on a leaning column element. The leaning column consists of rigid truss elements which are 
attached to the right-side of the sampled frame with rigid links and is restrained at the bottom with pinned support.

To validate the moment-rotation model, cyclic displacement history is affected to node 1 of the single degree of freedom system, shown in Fig. 4. The cyclic displacement history is shown in Fig.5 (Yu et. al 2000). Calibration of experimental results is shown in Fig.6 (Lignos 2008), while the results of OpenSees finite element model, are shown in Fig.7. Comparable results in these figures illustrate the validation of the applied finite element model.

It is shown that the variability of hysteresis model parameters, (e.g. strength, ductility and hysteretic energy capacity), has a minor effect on uncertainties of seismic performance of structures (Porter et al. 2002). In contrast of pre-collapse limit states which is considered in (Porter et al. 2002), it is shown that collapse limit state could be significantly affected while considering aforementioned uncertainty sources (Ibarra and Krawinkler 2005). This is due to the large variability of these parameters in nonlinear range of structural behavior, which normally the structure will go through before collapse, and the inability to accurately evaluate these parameters in the nonlinear range.

Definition of moment rotation backbone curve (Fig.8) and hysteretic rules are based on strength and ductility parameters. In this study, pre-capping plastic deformation $\left(\theta_{\mathrm{p}}\right)$, post-capping deformation range $\left(\theta_{\mathrm{pc}}\right)$ and the reference energy dissipation capacity of the component $(\Lambda)$ are assumed as the ductility parameters. The ratio of capping strength to yield strength $\left(\mathrm{M}_{\mathrm{c}} / \mathrm{M}_{\mathrm{y}}\right)$ is considered as the strength parameter. According to experimental tests, log-normal probability distributions are assigned to these parameters representing epistemic uncertainty. Median and logarithmic standard deviation of these parameters, for each component, are summarized in table 
(2) (Lignos 2008). These values are derived based on the statistical analysis of experimental results for various types of steel moment connections instead of the reduced beam section (RBS). Modeling uncertainties associated with the panel zone are neglected because it is presumed that ductile structural design ensures occurrence of the plastic hinges outside of the panel zone. Other uncertainties due to element level modeling (such as residual strength) and system level modeling (such as live load, dead load) are neglected for simplicity. Newmark's constant average acceleration procedure is applied as the integration method. To achieve the efficient time history dynamic analysis the time interval of a strong ground motion is assumed as the integration step. A_damping ratio coefficient with a value equal to 5\% of critical damping is assumed and stiffness and mass proportional Rayleigh damping is applied for beam and column elements.

To reduce the computational effort, due to required number of analysis towards realization of modeling parameter uncertainties, number of independent variables is reduced via consideration of full correlation between variables in each component and between components in the building. Therefore, four meta random variables are considered, beam strength (BS) (i.e. $M c / M_{y}$ for beams), column strength (CS) (i.e. $\mathrm{Mc} / \mathrm{M}_{\mathrm{y}}$ for columns), beam ductility (BD), (i.e. $\theta_{\mathrm{p}}, \theta_{\mathrm{pc}}, \Lambda$ for beams) and column ductility (CD) (i.e. $\theta_{\mathrm{p}}, \theta_{\mathrm{pc}}, \Lambda$ for columns) (Liel et al. 2009). Defined strength and ductility meta-variables are assumed to be fully correlated with similar variables and among similar components. Assuming standard logarithmic probability distribution for each metavariable, probability of each meta-variable can be mapped into probability of its components.

\section{Strong ground motions selection}

Assessment of seismic demand and relevant uncertainties are implemented through excitation of structures applying several acceleration time histories. These time histories must represent the 
seismic hazard at several return periods, and must be selected such that describe intensity, frequency content and duration with sufficient inclusiveness. The sufficiency and efficiency of several record sets are investigated by (Medina 2004). According to (Medina 2004), a set of 40 records entitled as LMSR-N ${ }^{1}$ (with $6.5 \leq \mathrm{Mw}<7$ and $13 \mathrm{~km}<\mathrm{R}<40 \mathrm{~km}$ ) are proven to be sufficient and efficient enough to characterize the variability of seismic demand while collapse limit state under ordinary ground motions are considered. Consequently in the present research, the mentioned records are applied to carry out the seismic demand evaluation of the case study subjected to ordinary ground motions.

\section{Effects of CQ applying fuzzy inference systems}

Mean and standard deviation (SD) of modeling parameters are affected by the quality of construction. Poor construction quality results in lower mean value and higher dispersion (Li and Ellingwood 2008). Three levels of construction quality are considered, and each level affects the median and SD values of meta-variable components. To achieve modeling variables statistical parameters for various CQ levels, median and standard deviation are unchanged for good CQ with respect to their experimental values. Due to scarcity of experimental data presenting effects of construction quality on modeling parameters, it is assumed that this effect can be involved in seismic fragility analysis by simply modifying the strength and ductility of the structure applying similar coefficients employed in previous researches (such as Rajeev and Tesfamariam 2012). For average CQ, the median value is decreased $25 \%$ and $\mathrm{SD}$ is increased $25 \%$ with respect to their values for good CQ. For poor CQ, the median value is decreased $40 \%$ and SD is increased $40 \%$ with respect to their values for good CQ. Although (Rajeev and Tesfamariam 2012)

\footnotetext{
${ }^{1}$ Large Magnitude Short Distance
} 
emphasized on concrete structures, it is assumed that similar pattern can be used to modify strength and ductility parameters for the case study which is a steel frame towards involving construction quality effects on fragility estimation. Median and standard deviation of modeling parameters are presented in table (3) for various CQ indices. Assigning membership functions to these linguistic values can be regarded as a form of data compression, known as granulation. For instance, granulations of median values for $\theta_{p}, \theta_{P C}, \Lambda$ of beams are shown in Fig.9. Granulation of other parameters would be the same.

\section{Collapse fragility curves}

Collapse fragility curve of the structure, which shows the probability of reaching or exceeding collapse while the structure is affected by strong ground motion with intensity measure $\left(\boldsymbol{i m}_{\boldsymbol{i}}\right)$, is represented by equation (4). In this equation, $\mu_{L n\left(i m_{c}\right)}$ is the mean and $\sigma_{L n\left(i m_{c}\right)}$ is the standard deviation of collapse probability function and $\Phi$ is the standard Gaussian distribution function. It is shown that both mean and standard deviation values of collapse fragility curve are affected while modeling uncertainty is involved (Liel et al. 2009).

$P\left(C \mid I M=i m_{i}\right)=\Phi\left(\frac{\operatorname{Ln}\left(i m_{i}\right)-\mu_{\operatorname{Ln}\left(i m_{c}\right)}}{\sigma_{\operatorname{Ln}\left(i m_{c}\right)}}\right)$

Incremental dynamic analysis (IDA) is the most common and consistent method to derive analytical collapse fragility curve of structures. In this method, the structure is excited by a number of earthquake records, which are representatives of site seismic hazard, with increasing level of intensity measure (IM). Plotting IM versus structural response parameter referred to as engineering demand parameter (EDP), represents IDA curves (Vamvatsikos and Cornell 2009). IDA curves corresponding to two scenarios for assumed case study are shown in Fig.10. In each 
IDA curve a point is the representative of sideway collapse limit state, which is defined as the intensity measure (IM) of strong ground motion by which the excited structure undergoes dynamic instability. In other words, $I M_{\text {Collapse }}$ is defined as the intensity measure of last-converged point on an IDA curve. Fitting a log-normal probability distribution function to $I M_{\text {Collapse }}$ values, and applying least square method, results in collapse fragility curve for the assumed structure (Zareian et al. 2010).

With simplifying assumptions, mean estimate (Zareian and Krawinkler 2007, Benjamin and Cornell 1970) and confidence interval (Ellingwood 2009) method have been applied to incorporate the effects of modeling uncertainty in collapse fragility curve. The former assumes that only variance of collapse fragility curve is changed affecting modeling uncertainty. On the other hand, the latter assumes the median is affected. Monte Carlo simulation method (Rubinstein 1981) is considered to be the more precise solution of the problem, in which thousands of ensembles for modeling parameter and nonlinear dynamic analysis of structure for each realization are required. This method is very elaborative due to the computational effort required in nonlinear dynamic analysis, which is needed to be repeated several times.

Applying a predefined regressed function as response surface, response surface-based Monte Carlo simulation has been proposed as an alternative to direct time history dynamic analysis to reduce the computational effort in the context of the previous investigations (Liel et al. 2009). In this method, first, fixed format of the functions is interpolated to the limited number of simulations of modeling variables as inputs, which lead to resultant means, and standard deviations of collapse fragility curves, as outputs of the functions. In the following step, means and standard deviations of collapse fragility curves for a large number of simulations of modeling 
parameters are calculated by applying derived analytical functions instead of direct nonlinear dynamic analysis, used in full Monte Carlo method. The price of efficiency in analysis time in the response surface-based Monte Carlo method is the loss of accuracy in approximated collapse fragility curves.

Quadratic response surfaces are considered in this paper (equations (5) and (6)) which represent the median and dispersion of collapse fragility curve as functions of modeling parameters. Constant coefficients of these functions are calculated through regression analysis to limit the number of realizations for modeling parameters and analytically derived means and standard deviations of collapse fragility curves. To achieve this primary goal, each meta-variable is perturbed \pm 1 away from zero (which corresponds to $\pm 1 \sigma$ perturbation away from the mean of meta variable components). Totally $\left(4^{3}=64\right)$ perturbations are implemented and for each perturbation collapse fragility curve of the structure is achieved through incremental dynamic analysis of the frame.

$$
\begin{aligned}
& \mu_{c}=C_{0}+C_{1}(C D)+C_{2}(B D)+C_{3}(C S)+C_{4}(B S)+C_{5}(C D)(B D)+C_{6}(C D)(C S)+C_{7}(C D)(B S)+ \\
& C_{8}(B D)(C S)+C_{9}(B D)(B S)+C_{10}(C S)(B S)+C_{11}(C D)^{2}+C_{12}(B D)^{2}+C_{13}(C S)^{2}+C_{14}(B S)^{2} \\
& \sigma_{c}=C^{\prime}{ }_{0}+C^{\prime}{ }_{1}(C D)+C_{2}^{\prime}(B D)+C_{3}^{\prime}(C S)+C_{4}^{\prime}(B S)+C^{\prime}(C D)(B D)+C^{\prime}(C D)(C S)+C^{\prime}{ }_{7}(C D)(B S)+ \\
& C^{\prime}{ }_{8}(B D)(C S)+C_{9}^{\prime}(B D)(B S)+C^{\prime}{ }_{10}(C S)(B S)+C^{\prime}{ }_{11}(C D)^{2}+C^{\prime}{ }_{12}(B D)^{2}+C_{13}^{\prime}(C S)^{2}+C^{\prime}{ }_{14}(B S)^{2}
\end{aligned}
$$

To involve the effects of construction quality and its interaction with modeling parameters on collapse fragility, calculation of collapse fragility curve and response surfaces are derived for each construction quality level. Coefficients of equations (5) and (6) are shown in table (4) for three levels of construction quality which are derived based on response surface fitting to achieved data. Median of IDA curves for three levels of CQ are presented in Fig.11. This figure shows considerable effects of CQ on the dynamic response of the sample frame. 


\section{Parametric study}

Construction quality uncertainty is involved through Sugeno-type fuzzy inference system. To construct the inference, six rules are considered according to the data shown in table (4). These rules are summarized in equation (7).

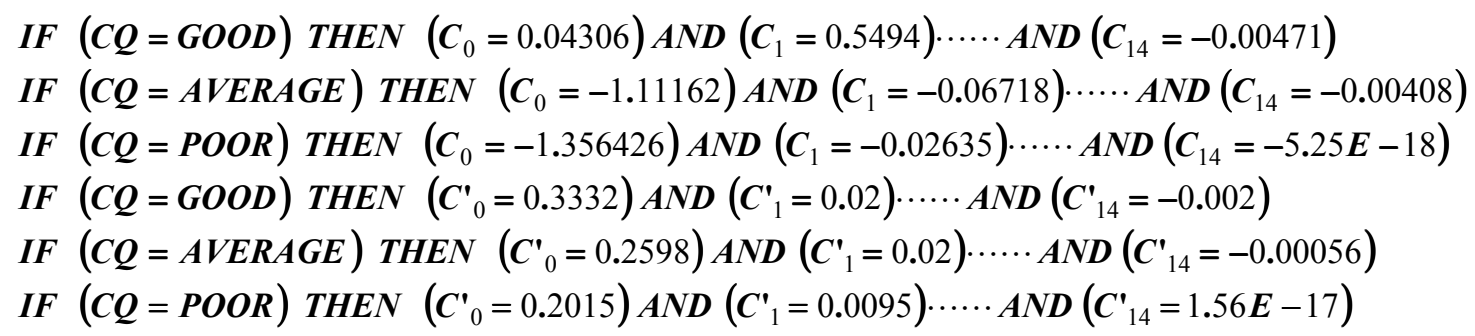

Considering weighted average method for defuzzification, coefficients of mean function (i.e. $\left.C_{0} \ldots C_{14}\right)$ and standard deviation function (i.e. $C^{{ }^{\prime}}{ }_{0} \ldots C^{\prime}{ }_{14}$ ), are calculated by the rules and the index of $\boldsymbol{C} \boldsymbol{Q}$ as input through Sugeno-type fuzzy inference system. Given brevity of some answers, interpolated response surfaces for the mean and the SD values are presented in Fig.12 and Fig.13, respectively. Since the mean and the SD values are more sensitive to ductility metavariables, these figures are plotted for $\mathrm{BD}$ and $\mathrm{CD}$ values, while strength meta-variables are set to their mean $(\mathrm{BS}=0, \mathrm{CS}=0)$.

\section{Monte Carlo simulation and derivation of final fragility curve}

To achieve a final fragility curve, while involving record-to-record, modeling and construction quality uncertainty effects, Monte Carlo simulation is applied. In the first step of this method, 100 uniformly-distributed values for $\boldsymbol{C Q}$ are simulated in interval[1,3]. For each simulation, coefficients of response functions (equations (5) and (6)) are calculated based on the trained fuzzy inference system. In the second step, simulations of modeling parameters are performed. 
100 simulations for each of the modeling meta-variables (i.e. $\boldsymbol{C D}, \boldsymbol{B D}, \boldsymbol{C S}, \boldsymbol{B S}$ ) are obtained by random number generation and based on a standard log-normal probability distribution function (with $\mu=0$ and $\sigma=1$ ).Mean and standard deviation values are calculated for each simulated metavariable and according to the response surfaces.Totally 10000 collapse fragility curves are calculated for various levels of construction quality and meta-variable values. The final step is to achieve final fragility function based on the results obtained from Monte Carlo simulations. For each spectral accelerations, the expected value of collapse probabilities, which are calculated according to 10000 collapse fragility curves, is considered as the final fragility probability (Liel et al. 2009). Collapse fragility curves of the sample frame with modeling and construction quality uncertainties and without these uncertainties are compared in Fig.14. Furthermore, the effects of modeling uncertainty at each construction quality level are evaluated by the response surface method (Fig.15). Median and standard deviation values of collapse fragility curve are presented in table (5).

Design spectra for $2 \%$ and $10 \%$ probability of exceedance hazard levels are shown in Fig.16, based on the Iranian seismic code 2800 (No. 2800 seismic design Standard. 2005). For the sample frame, spectral accelerations of first-mode period for these two hazard levels are $0.8 \mathrm{~g}$ and $0.53 \mathrm{~g}$, respectively. Probability of collapse of the sample frame for these two seismic hazard levels are compared in table (6), considering the derived fragility curves.

\section{Summary and Conclusion}

In this paper collapse fragility curves of structures are derived while involving various sources of modeling and construction quality uncertainties. Modeling uncertainties are considered through the application of full quadratic response surfaces. Coefficients of response surfaces are 
calculated for each construction quality levels. Fuzzy inference system is applied to predict response surface coefficients for various values of construction quality index. Through the application of this method, interaction of modeling and CQ uncertainty is taken into consideration by the Monte Carlo simulation of response surface coefficients and modeling metavariables. As a case study, collapse fragility curve of a 3-story moment resisting frame is calculated. Collapse fragility curves are compared while various sources of uncertainties are considered.

As shown in Fig.14, interaction of uncertainty due to modeling parameters and construction quality affect both the median and the standard deviation of a collapse fragility curve. These sources cause a reduction in the median and an increment in the dispersion values of collapse fragility curve. Neglecting these effects causes underestimation of collapse fragility probabilities, which shows the importance of considering modeling uncertainty effects on collapse fragility curves. Collapse fragility curves for the sample frame in various construction quality levels are presented in Fig.15. Comparison of Figs.14 and 15 shows that considering the interaction of modeling and CQ uncertainty sources increases the dispersion of collapse fragility curve while the median value is decreased as compared with good CQ collapse fragility curve and is increased comparing with average or poor CQ collapse fragility curves.

In Fig.15, fragility curves are achieved by utilizing the response surface method for each construction quality level separately. It can be concluded that construction quality is a dominant factor in the probability of collapse. Also while $\mathrm{CQ}=$ Poor, the structure will be more brittle. Probability of collapse for the sample frame in two hazard levels $(2 \% / 50$ years and $10 \% / 50$ years $)$ are compared in table (6). It can be concluded that the interaction of modeling and CQ uncertainties increase $60 \%$ and $53 \%$ in $2 \% / 50$ years and $10 \% / 50$ years hazard levels, 
respectively. While the interaction of uncertainties is not considered and only modeling uncertainty is considered, this increment is predicted as $42 \%$ and $16 \%$, respectively. This fact shows the importance of considering the interaction of modeling and CQ uncertainties in regions that good construction quality is not guaranteed such as in underdeveloped or some developing countries. Furthermore, considerable effect of CQ on probability of collapse is demonstrated. Modified Ibarra-Krawinkler moment-rotation model which is applied in this study does not have the capability to consider the interaction of axial load and the bending moment (P-M interaction) in simulating the hysteretic response of steel columns. Since the presence of the axial load will decrease the moment capacity of a section, it seems that considering this effect will increase the probability of collapse which is obtained in the current study.

Although an inclusive seismic risk analysis of structures must be based on actual field data, the case study investigated in this paper shows the efficiency of the proposed method. Comprehensive experimental data representing effects of construction quality on modeling parameters of steel moment frame structures are needed to make the results practical in seismic risk analysis.

Quality of construction for a building may be determined by visual inspection, expert opinions or advanced tests. According to quality of construction for a region; seismic hazard analysis of the region can be integrated with the correspondent fragility curve to evaluate the mean annual frequency of collapse, which is an important factor for risk management and decision making.

\section{References}

Armenia earthquake reconnaissance report .1989. Earthquake Engineering Research Institute.

Bam earthquake report. 2003. Iranian structural engineering organization, province of Kerman. 
Benjamin JR and Cornell CA. 1970. Probability, statistics and decision for civil engineers New York: McGraw-Hill;

Deierlein, G. G. 2004. "Overview of a comprehensive framework for earthquake performance assessment." In Performance-Based Seismic Design Concepts and Implementation, Proceedings of an International Workshop, pp. 15-26.

Deierlein, G. G., H. Krawinkler, and C. A. Cornell. 2003 "A framework for performance-based earthquake engineering." Pacific conference on earthquake engineering.

Der Kiureghian, A. 2008. Analysis of structural reliability under parameter uncertainties. Probabilistic engineering mechanics, 23(4), 351-358.

Der Kiureghian, A. and Ditlevsen, O. 2009. Aleatory or epistemic? Does it matter? Structural Safety, 31(2), 105-112.

Dimova, S. L. and Negro, P. 2006. Assessment of seismic fragility of structures with consideration of the quality of construction. Earthquake spectra, 22(4), 909-936.

Ellingwood B. 2009. Quantifying and communicating uncertainty in seismic risk assessment. Structural Safety 31, 179-18.

Erberik, M. A. 2008. Generation of fragility curves for Turkish masonry buildings considering in-plane failure modes. Earthquake Engineering \& Structural Dynamics, 37(3), 387-405.

Federal Emergency Management Agency (FEMA). (2009). Quantification of Building Seismic Performance Factors. 
Ibarra, L. F. and Krawinkler, H. 2005. Global collapse of frame structures under seismic excitations.Pacific Earthquake Engineering Research Center.

Kappos, A. J. and Panagopoulos, G. 2010. Fragility curves for reinforced concrete buildings in Greece. Structure and Infrastructure Engineering, 6(1-2), 39-53.

Kazantzi, A. K., Vamvatsikos, D. and Lignos, D. G. 2014. Seismic performance of a steel moment-resisting frame subject to strength and ductility uncertainty. Engineering Structures, 78, $69-77$.

Krawinkler, H., Zareian, F., Lignos, D. G. and Ibarra, L. F. 2009. Prediction of collapse of structures under earthquake excitations. In Proceedings of the 2nd International Conference on Computational Methods in Structural Dynamics and Earthquake Engineering (COMPDYN 2009), Rhodes, Greece, CD-ROM paper, paper no. CD449 (pp. 22-24).

Kwakernaak, H. 1978. Fuzzy random variables-I. Definitions and theorems. Information Sciences, 15(1), 1-29.

Li, Q. and Ellingwood, B. R. 2008. Damage inspection and vulnerability analysis of existing buildings with steel moment-resisting frames. Engineering Structures, 30(2), 338-351.

Liel, A. B., Haselton, C. B., Deierlein, G. G. and Baker, J. W. 2009. Incorporating modeling uncertainties in the assessment of seismic collapse risk of buildings. Structural Safety, 31(2), 197-211.

Lignos D. 2008. "Sideway collapse of deteriorating structural systems under seismic excitations", PhD dissertation, Department of Civil Engineering, Stanford University. 
Moeindarbari, H., Malekzadeh, M., and Taghikhany, T.. "Probabilistic analysis of seismically isolated elevated liquid storage tank using multi-phase friction bearing." Earthquakes and Structures 6.1 (2014): 111-125.

Mamdani, E. H. 1976. Advances in the linguistic synthesis of fuzzy controllers.International Journal of Man-Machine Studies, 8(6), 669-678.

Medina, R. A. and Krawinkler, H. 2004. Seismic demands for nondeteriorating frame structures and their dependence on ground motions (Doctoral dissertation, Pacific Earthquake Engineering Research Center).

Möller, B. Graf, W. and Beer M. 2003. Safety assessment of structures in view of fuzzy randomness.Computers\& structures, 81(15), 1567-1582.

Möller, B., Graf, W. and Beer M. 2000. Fuzzy structural analysis using $\alpha$-level optimization. Computational Mechanics, 26(6), 547-565.

No. 2800 seismic design Standard. 2005. "2800-05. Iranian code of practice for seismic resistant design of buildings.

OpenSees .2002. Open system for Earthquake Engineering Simulation, Pacific Earthquake Engineering Research Center, http://peer.berkeley.edu

Porter K. A., Beck J. L. and Shaikhutdinov, R. V. 2002. Sensitivity of building loss estimates to major uncertain variables. Earthquake Spectra, 18(4), 719-743.

Rahnama, M., and Krawinkler H. 1993. Effects of soft soil and hysteresis model on seismic demands. No. 108.John A. Blume Earthquake Engineering Center, 
Rajeev, P. and Tesfamariam, S. 2012. Seismic fragilities for reinforced concrete buildings with consideration of irregularities. Structural Safety, 39, 1-13.

Rubinstein RY. 1981.Simulation and the Monte Carlo method. New York: John Wiley and Sons Sanada, Y., Ali, N., Maeda, M., Toshimi, K. and Mohammad, R. G. 2004. Building damage around Bam seismological observatory following the Bam, Iran earthquake of Dec. 26, 2003.

Sivaselvan, M. V. and Reinhorn, A. M. (2002). Collapse analysis: Large inelastic deformations analysis of planar frames. Journal of Structural Engineering, 128(12), 1575-1583.

Sugeno, M. 1985. An introductory survey of fuzzy control.Information sciences, 36(1), 59-83.

Tesfamariam, S. and Saatcioglu, M. 2010. Seismic vulnerability assessment of reinforced concrete buildings using hierarchical fuzzy rule base modeling.Earthquake Spectra, 26(1), 235256.

UBC. 1997, “Uniform Building Code," International Conference of Building Officials, Whittier, California.

Vamvatsikos, D. and Cornell, C. A. 2002. Incremental dynamic analysis. Earthquake Engineering \& Structural Dynamics, 31(3), 491-514.

Wang, Z. 2008. "A preliminary report on the Great Wenchuan Earthquake."Earthquake Engineering and Engineering Vibration 7.2: 225-234.

Yu, Q. S., Gilton, C., and Uang, C. M. 2000. Cyclic response of RBS moment connections: loading sequence and lateral bracing effects (Vol. 99, No. 13). Dept. of Structural Engineering, Univ. of California, San Diego. 
Zadeh, L. A. 1994. Fuzzy logic, neural networks, and soft computing.Communications of the $A C M, 37(3), 77-84$.

Zareian F and Krawinkler H. 2007.Assessment of probability of collapse and design for collapse safety.EarthquakeEngineering\&Structural Dynamics 36(13): 1901-1944.

Zareian F. and Krawinkler H. 2006. "Simplified performance-based earthquake engineering." PhD diss., Stanford University,

Zareian, F., Krawinkler, H., Ibarra, L. and Lignos, D. 2010. Basic concepts and performance measures in prediction of collapse of buildings under earthquake ground motions. The Structural Design of Tall and Special Buildings, 19(1-2), 167-181.

Zimmermann, H. J. 2001. Fuzzy set theory-and its applications. Springer. 
Table(1). Gravity load assumptions

\begin{tabular}{|c|c|}
\hline Dead load of regular story & $500 \mathrm{~kg} / \mathrm{m}^{2}$ \\
\hline Partition load & $100 \mathrm{~kg} / \mathrm{m}^{2}$ \\
\hline Live load of regular story & $200 \mathrm{~kg} / \mathrm{m}^{2}$ \\
\hline Dead load of roof & $520 \mathrm{~kg} / \mathrm{m}^{2}$ \\
\hline Live load of roof & $150 \mathrm{~kg} / \mathrm{m}^{2}$ \\
\hline Perimeter wall load & $580 \mathrm{~kg} / \mathrm{m}$ \\
\hline
\end{tabular}


Table(2). Statistical parameters of modeling parameters based on experimental results (Lignos 2008)

\begin{tabular}{|c|c|c|c|c|c|c|c|c|}
\hline Component & $\begin{array}{c}\text { Median } \\
\theta_{\mathrm{p}}(\mathrm{rad})\end{array}$ & $\begin{array}{c}\sigma_{\theta \mathrm{p}} \\
(\mathrm{rad})\end{array}$ & $\begin{array}{c}\text { Median } \\
\theta_{\mathrm{pc}}(\mathrm{rad})\end{array}$ & $\begin{array}{c}\sigma_{\theta \mathrm{pc}} \\
(\mathrm{rad})\end{array}$ & $\begin{array}{c}\text { Median } \\
\Lambda\end{array}$ & $\sigma_{\Lambda}$ & $\begin{array}{c}\text { Median } \\
\mathbf{M}_{\mathrm{c}} / \mathbf{M}_{\mathrm{y}}\end{array}$ & $\sigma_{\mathrm{Mc} / \mathrm{My}}$ \\
\hline Beam & 0.025 & 0.43 & 0.16 & 0.41 & 1.00 & 0.43 & 1.11 & 0.05 \\
\hline Column & 0.011 & 0.57 & 0.07 & 0.92 & 0.4 & 0.96 & 1.11 & 0.05 \\
\hline
\end{tabular}


Table(3). Values of each meta-variable for various construction quality

\begin{tabular}{|c|c|c|c|c|}
\hline Meta Variable & Parameter & $\begin{array}{c}\text { Construction } \\
\text { Quality }\end{array}$ & Median & SD \\
\hline \multirow{9}{*}{$\begin{array}{c}\text { Beam } \\
\text { Ductility (BD) }\end{array}$} & \multirow{3}{*}{$\theta_{\mathrm{p}}$} & GOOD & 0.025 & 0.43 \\
\hline & & AVERAGE & 0.01875 & 0.5375 \\
\hline & & POOR & 0.015 & 0.60 \\
\hline & \multirow{3}{*}{$\theta_{\mathrm{pc}}$} & GOOD & 0.16 & 0.41 \\
\hline & & AVERAGE & 0.12 & 0.5125 \\
\hline & & POOR & 0.096 & 0.5766 \\
\hline & \multirow{3}{*}{$\Lambda$} & GOOD & 1 & 0.43 \\
\hline & & AVERAGE & 0.75 & 0.5375 \\
\hline & & POOR & 0.6 & 0.6047 \\
\hline \multirow{8}{*}{$\begin{array}{c}\text { Column } \\
\text { Ductility (CD) }\end{array}$} & \multirow{3}{*}{$\theta_{\mathrm{p}}$} & GOOD & 0.011 & 0.57 \\
\hline & & AVERAGE & 0.00825 & 0.7125 \\
\hline & & POOR & 0.0066 & 0.8016 \\
\hline & \multirow{3}{*}{$\theta_{\mathrm{pc}}$} & GOOD & 0.07 & 0.92 \\
\hline & & AVERAGE & 0.053 & 1.15 \\
\hline & & POOR & 0.042 & 1.2938 \\
\hline & \multirow{2}{*}{$\Lambda$} & GOOD & 0.4 & 0.96 \\
\hline & & AVERAGE & 0.3 & 1.2 \\
\hline
\end{tabular}




\begin{tabular}{|c|c|c|c|c|}
\hline & & POOR & 0.24 & 1.35 \\
\hline \multirow{2}{*}{$\begin{array}{c}\text { Beam } \\
\text { Strength (BS) }\end{array}$} & \multirow{2}{*}{$\mathrm{M}_{\mathrm{c}} / \mathrm{M}_{\mathrm{y}}$} & AVERAGE & 0.8325 & 0.0625 \\
\cline { 3 - 5 } & & POOR & 0.666 & 0.0703 \\
\cline { 3 - 5 } & & GOOD & 1.11 & 0.05 \\
\hline \multirow{2}{*}{$\begin{array}{c}\text { Column } \\
\text { Strength (CS) }\end{array}$} & \multirow{2}{*}{$\mathrm{M}_{\mathrm{c}} / \mathrm{M}_{\mathrm{y}}$} & AVERAGE & 0.8325 & 0.0625 \\
\cline { 3 - 5 } & & & 0.666 & 0.0703 \\
\cline { 3 - 5 } & & POOR & & \\
\hline
\end{tabular}


Table(4). Coefficients of response surfaces

\begin{tabular}{|c|c|c|c|c|c|c|c|}
\hline \multirow{2}{*}{ Coefficient } & \multicolumn{3}{|c|}{ Construction Quality } & \multirow{2}{*}{ Coefficient } & \multicolumn{3}{|c|}{ Construction Quality } \\
\hline & Good & Average & Poor & & Good & Average & Poor \\
\hline $\boldsymbol{C}_{0}$ & 0.0434 & -1.1162 & -1.3564 & $C^{\prime}{ }_{0}$ & 0.3332 & 0.2599 & 0.2015 \\
\hline$C_{1}$ & 0.5494 & -0.0671 & -0.0263 & $C^{\prime}{ }_{1}$ & 0.0200 & 0.0201 & 0.0095 \\
\hline $\boldsymbol{C}_{2}$ & -0.0039 & -0.0013 & $-5.25 \mathrm{E}-18$ & $\mathrm{C}_{2}^{\prime}$ & 0.0017 & 0.0019 & $-8.39 \mathrm{E}-19$ \\
\hline$C_{3}$ & 0.0258 & 0.1680 & 0.0146 & $\mathrm{C}_{3}^{\prime}$ & 0.0029 & 0.0327 & 0.004517 \\
\hline$C_{4}$ & 0.0131 & 0.0054 & $6.30 \mathrm{E}-17$ & $\mathrm{C}_{4}^{\prime}$ & 0.0052 & 0.0019 & $-9.02 \mathrm{E}-18$ \\
\hline$C_{5}$ & -0.0039 & $-7.95 \mathrm{E}-05$ & $7.57 \mathrm{E}-17$ & $C^{\prime}{ }_{5}$ & 0.0034 & -0.0007 & $1.31 \mathrm{E}-17$ \\
\hline$C_{6}$ & 0.0286 & 0.0243 & 0.0033 & $\mathrm{C}_{6}{ }_{6}$ & -0.0044 & 0.0118 & -0.0032 \\
\hline$C_{7}$ & 0.0181 & -0.0040 & $-1.01 \mathrm{E}-05$ & $C^{\prime}{ }_{7}$ & 0.0047 & -0.0010 & $-4.71 E-05$ \\
\hline$C_{8}$ & -0.0036 & -0.0021 & $3.49 \mathrm{E}-17$ & $\mathrm{C}_{8}^{\prime}$ & 0.0034 & 0.0017 & $-5.18 \mathrm{E}-18$ \\
\hline $\boldsymbol{C}_{9}$ & -0.0006 & $-8.55 \mathrm{E}-05$ & $1.03 \mathrm{E}-16$ & $\mathrm{C}_{9}^{\prime}$ & 0.0003 & -0.0006 & $-1.87 \mathrm{E}-17$ \\
\hline$C_{10}$ & -0.0002 & 0.0085 & $-6.42 \mathrm{E}-17$ & $C^{\prime}{ }_{10}$ & 0.0033 & 0.0024 & $2.02 \mathrm{E}-17$ \\
\hline$C_{11}$ & -0.0126 & -0.1750 & -0.0155 & $C^{\prime}{ }_{11}$ & 0.0258 & -0.0452 & -0.0127 \\
\hline$C_{12}$ & 0.0038 & 0.0011 & $-1.01 \mathrm{E}-16$ & $C_{12}^{\prime}$ & -0.0045 & -0.0013 & $1.96 \mathrm{E}-17$ \\
\hline$C_{13}$ & -0.0385 & 0.1080 & -0.0008 & $C_{13}^{\prime}$ & -0.0097 & -0.0030 & 0.0002 \\
\hline$C_{14}$ & -0.0047 & -0.0041 & $-9.56 \mathrm{E}-17$ & $C^{\prime}{ }_{14}^{\prime}$ & -0.0020 & -0.0006 & $1.56 \mathrm{E}-17$ \\
\hline
\end{tabular}


Table(5). Median and standard deviation of collapse fragility curves, effects of modeling and CQ uncertainty

\begin{tabular}{|c|c|c|c|}
\hline & \multirow[b]{2}{*}{$\begin{array}{l}\text { Median } \\
\text { Value }\end{array}$} & \multirow[b]{2}{*}{$\begin{array}{c}\text { Standard } \\
\text { Deviation }\end{array}$} \\
\hline & & & \\
\hline \multicolumn{2}{|c|}{ Neglecting Modeling and CQ uncertainty } & 1.066 & 0.340 \\
\hline \multicolumn{2}{|c|}{$\begin{array}{l}\text { Considering interaction of Modeling and CQ } \\
\text { uncertainty }\end{array}$} & 0.488 & 0.576 \\
\hline \multirow{3}{*}{$\begin{array}{l}\text { Considering modeling uncertainty } \\
\text { by response surface method }\end{array}$} & GOOD CQ & 0.711 & 0.387 \\
\hline & $\begin{array}{l}\text { AVERAGE } \\
\text { CQ }\end{array}$ & 0.344 & 0.292 \\
\hline & POOR CQ & 0.254 & 0.204 \\
\hline
\end{tabular}


Table(6). Probability of collapse for $2 \% / 50$ years and $10 \% / 50$ years seismic hazard levels

\begin{tabular}{|c|c|c|}
\hline Hazard Level & $\mathbf{2 \% / 5 0}$ years & $\mathbf{1 0 \% / 5 0}$ years \\
\hline $\begin{array}{c}\text { Neglecting } \\
\text { modeling and CQ } \\
\text { uncertainties }\end{array}$ & $\mathbf{2 0 \%}$ & $\mathbf{2 \%}$ \\
\hline $\begin{array}{c}\text { Considering } \\
\text { Interaction of } \\
\text { modeling and CQ } \\
\text { uncertainties }\end{array}$ & $\mathbf{8 0 \%}$ & $\mathbf{5 5 \%}$ \\
\hline $\begin{array}{c}\text { Considering } \\
\text { modeling } \\
\text { uncertainty for } \\
\text { Good CQ }\end{array}$ & $\mathbf{6 2 \%}$ & $\mathbf{1 8 \%}$ \\
\hline $\begin{array}{c}\text { Considering } \\
\text { modeling } \\
\text { uncertainty for } \\
\text { Average CQ }\end{array}$ & $100 \%$ & $\mathbf{8 9 \%}$ \\
\hline $\begin{array}{c}\text { Considering } \\
\text { modeling } \\
\text { uncertainty for } \\
\text { Poor CQ }\end{array}$ & $100 \%$ & $100 \%$ \\
\hline
\end{tabular}


Fig. 1. Structural seismic damage due to poor construction quality (Bam earthquake report 2003)

Fig. 2. Considered uncertainty sources and corresponding methodologies

Fig. 3. The analytical model of the three-story, three-bay moment resisting frame under consideration

(a) 3D view of sample structure

(b) Two-dimensional frame model

Fig. 4. Single degree of freedom system

Fig. 5. Cyclic drift history applied to the single degree of freedom system (Yu et al. 2000)

Fig. 6. Results presented by Lignos (2008)

Fig 7. Results of OPENSEES model

Fig 8. Moment-Rotation backbone model

Fig 9. Granulation of $\theta_{\mathrm{p}}, \theta_{\mathrm{pc}}$ and $\Lambda$ median values for beams

Fig 10. Examples of IDA curves for two scenarios (Upper figure $(B D=0, C D=0, C S=0, C D=0$ and $C Q$ $=1)$, Lower figure $(\mathrm{BD}=0, \mathrm{CD}=0, \mathrm{CS}=0, \mathrm{CD}=0$ and $\mathrm{CQ}=2)$ )

Fig 11. Median of sample IDA curves for various CQ

Fig 12. Interpolated response surfaces for mean values a. Good CQ, b. Average CQ and c. Poor $\mathrm{CQ}($ While $\mathrm{BS}=0$ and $\mathrm{CS}=0$ )
a. Good CQ
b. Average CQ
c. Poor CQ

Fig 13. Interpolated response surfaces for $S D$ values a. Good $C Q$, b. Average $C Q$ and c. Poor $\mathrm{CQ}($ While $\mathrm{BS}=0$ and $\mathrm{CS}=0$ )

Fig 14. Collapse fragility curves

Fig 15. Collapse fragility curves in various levels of CQ (modeling uncertainty considered without interaction with CQ uncertainty)

Fig 16. Design spectra for two hazard levels 

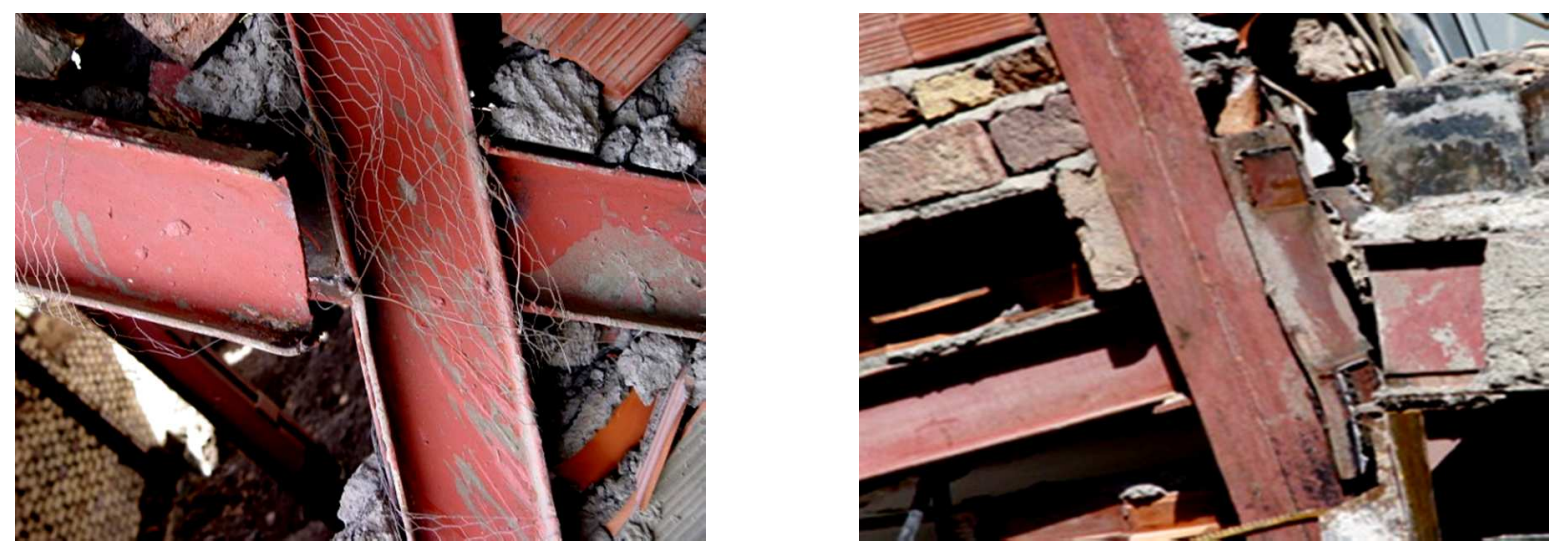


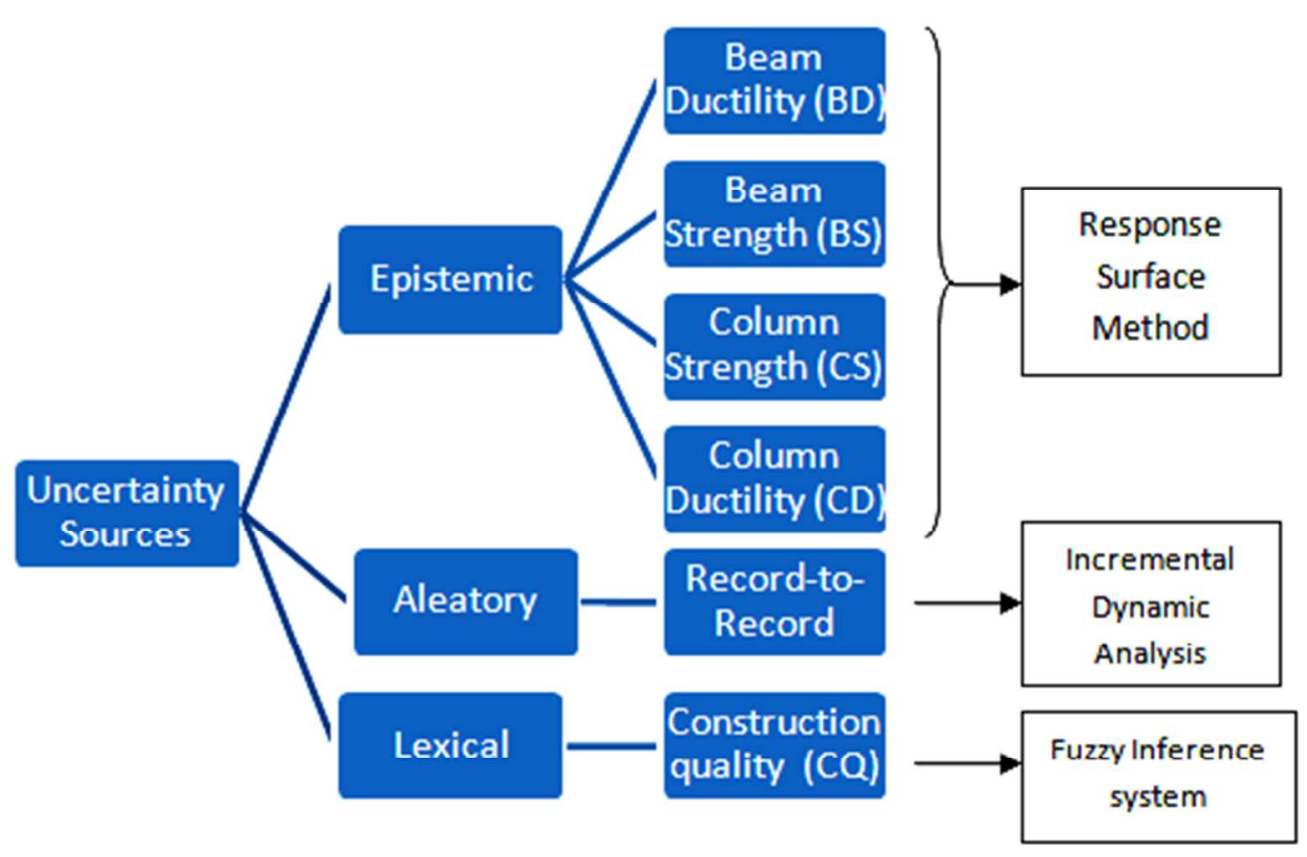

https://mc06.manuscriptcentral.com/cjce-pubs 

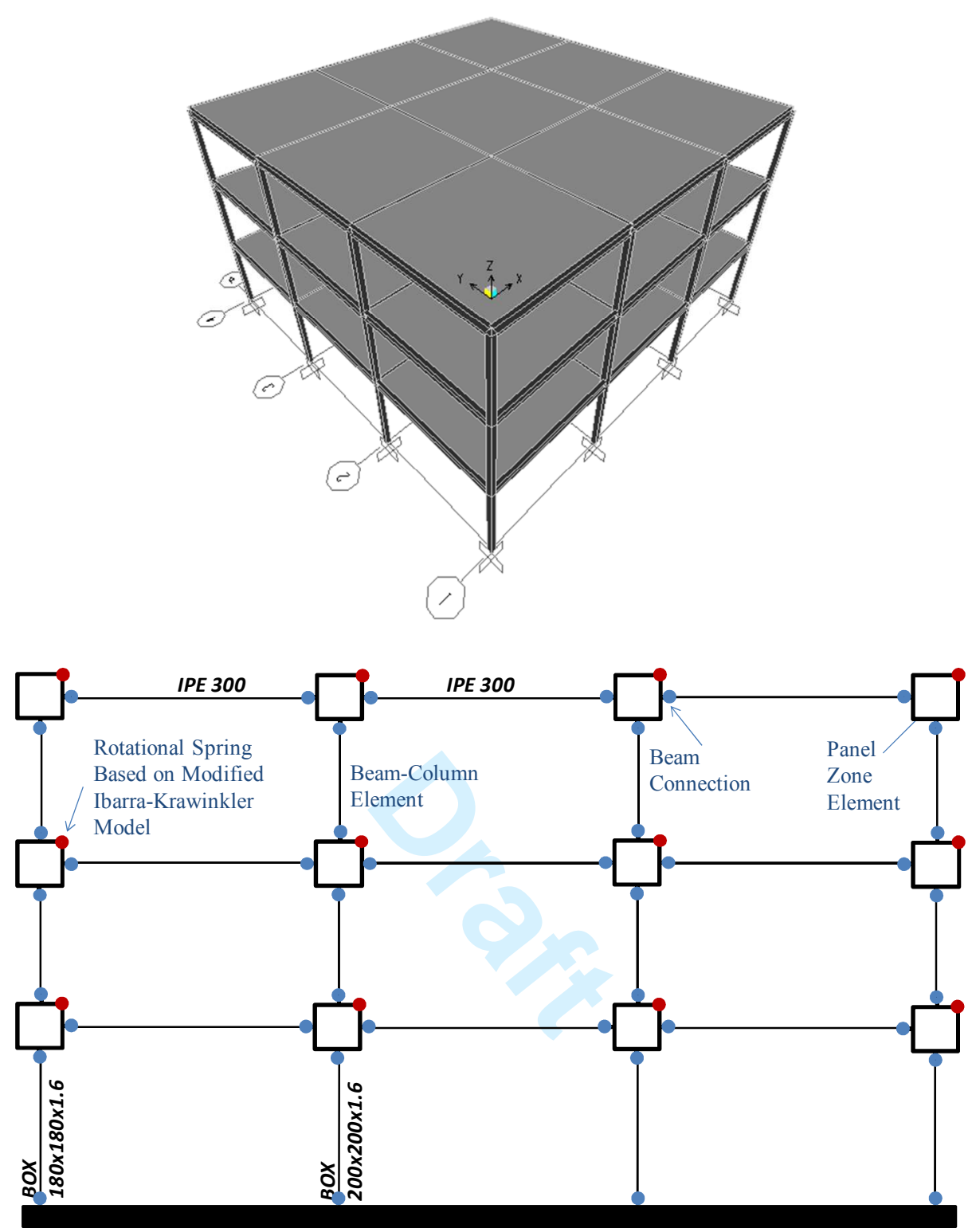


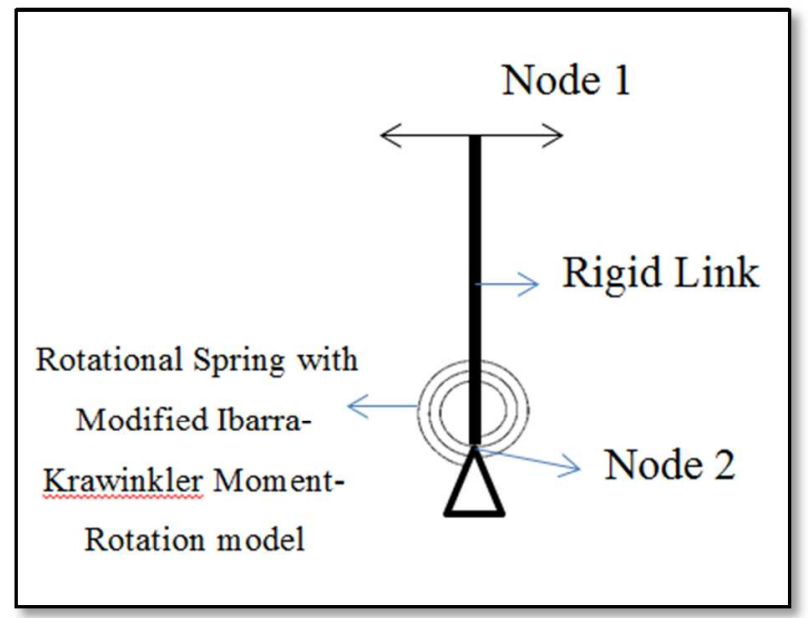

https://mc06.manuscriptcentral.com/cjce-pubs 


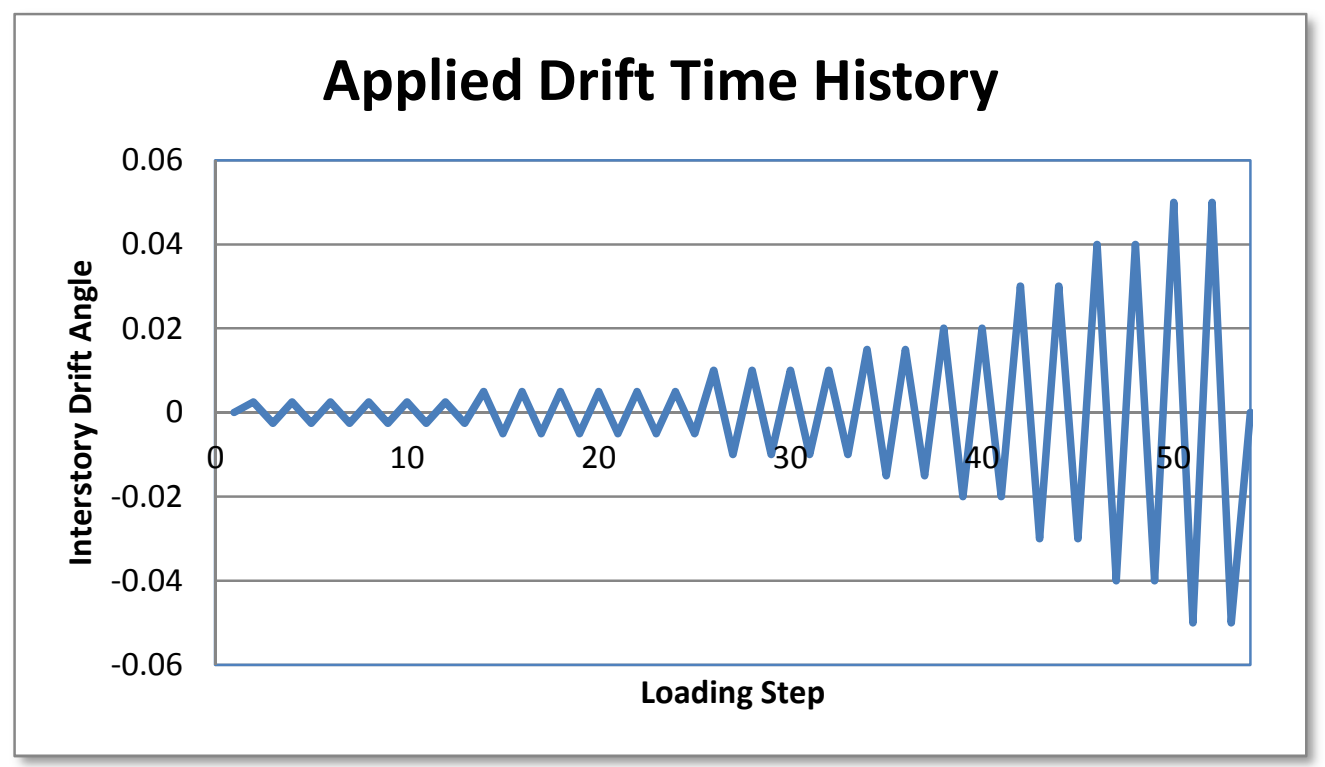




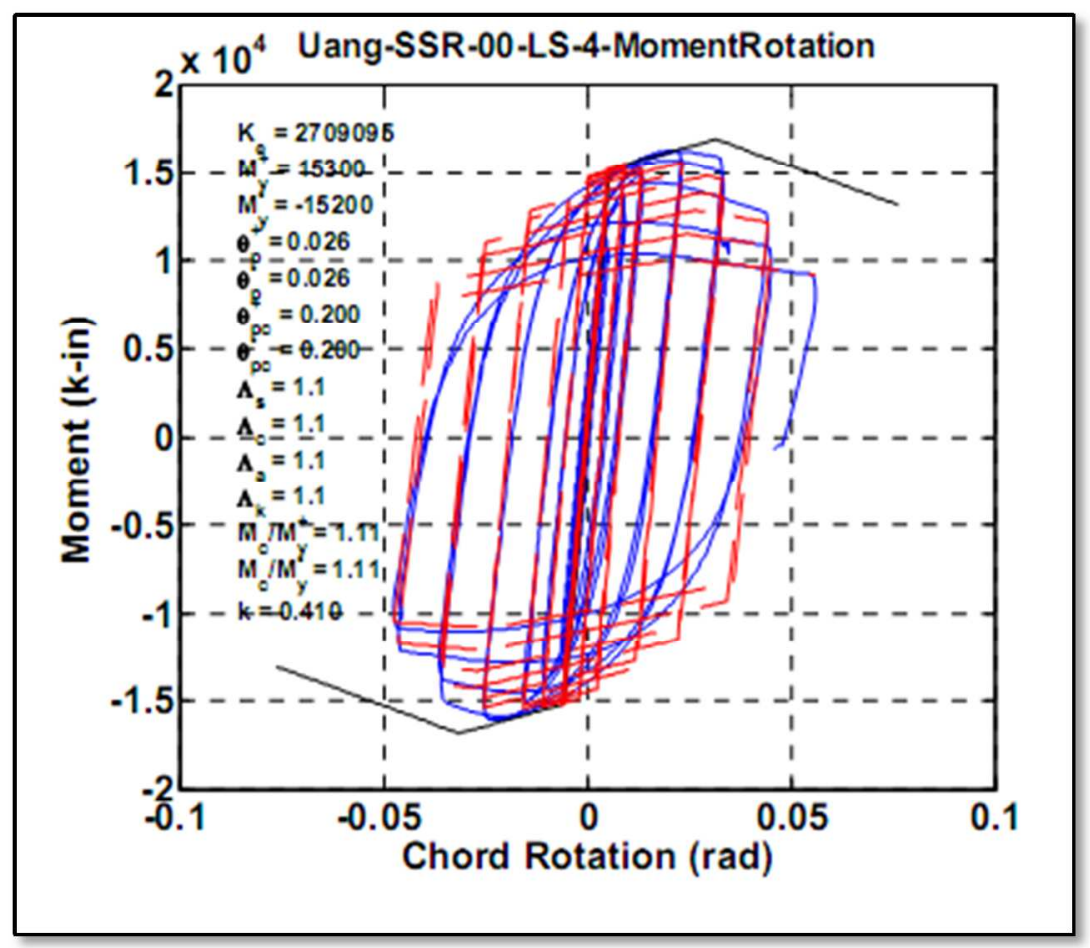

https://mc06.manuscriptcentral.com/cjce-pubs 


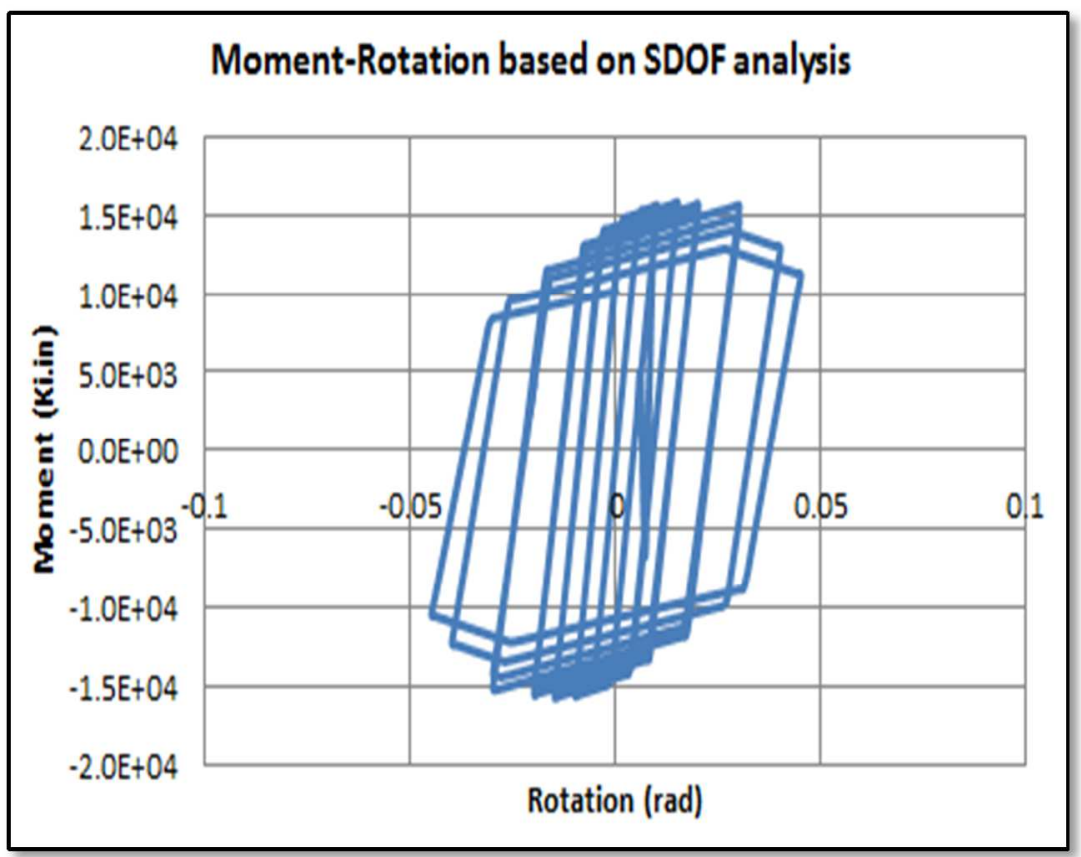

https://mc06.manuscriptcentral.com/cjce-pubs 


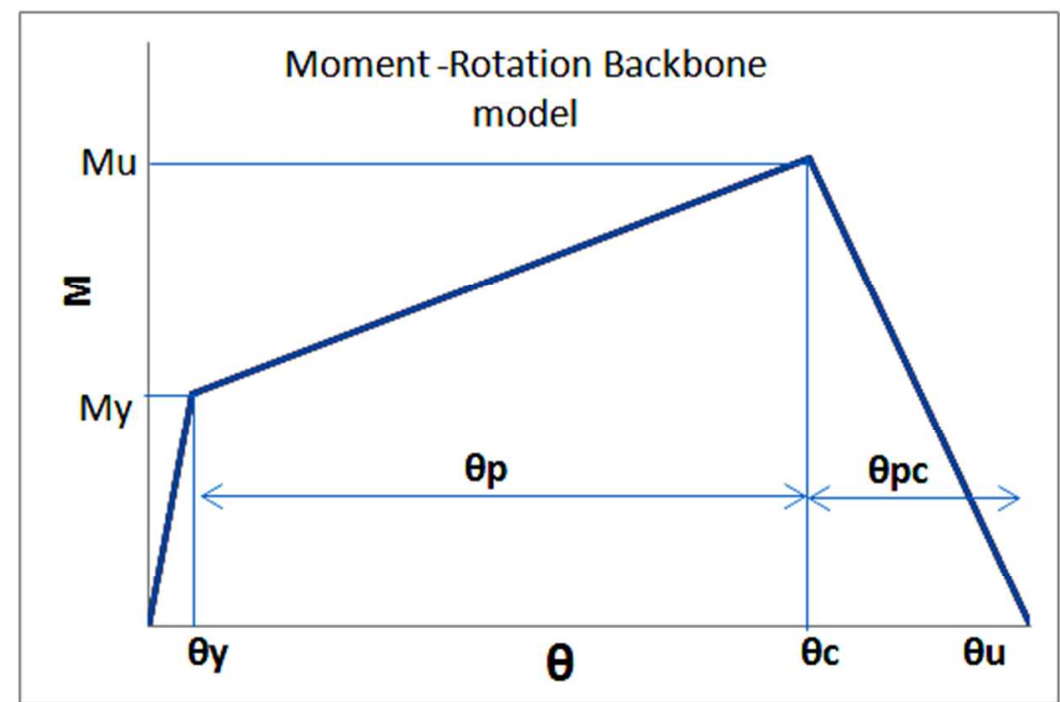

https://mc06.manuscriptcentral.com/cjce-pubs 
Granulation of median values of $\theta p c$ for beams

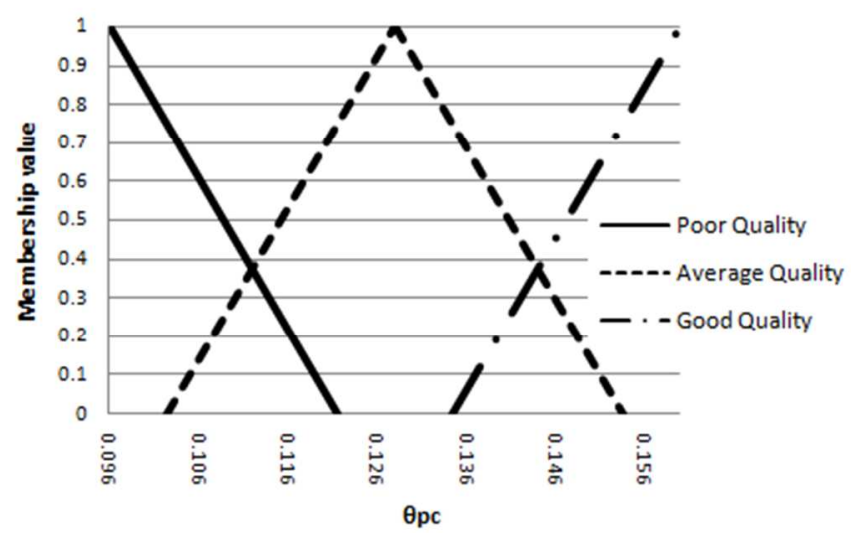

Granulation of median values of $\theta_{p}$ for Beams

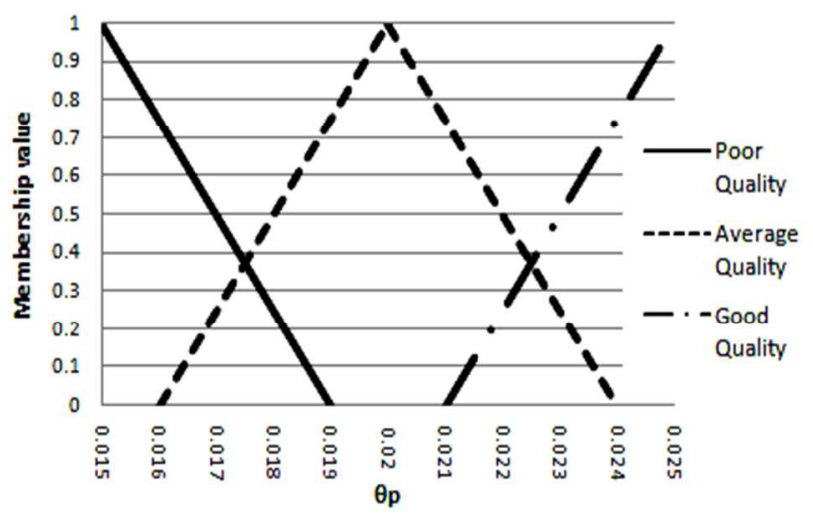

Granulation of median values of $\Lambda$ for beams

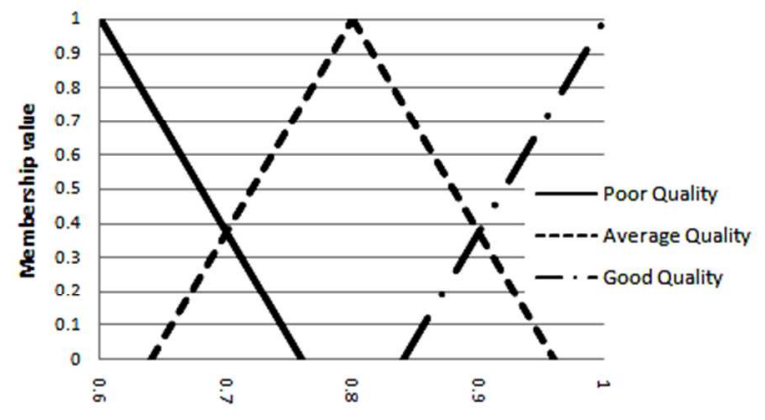

$\wedge$ 

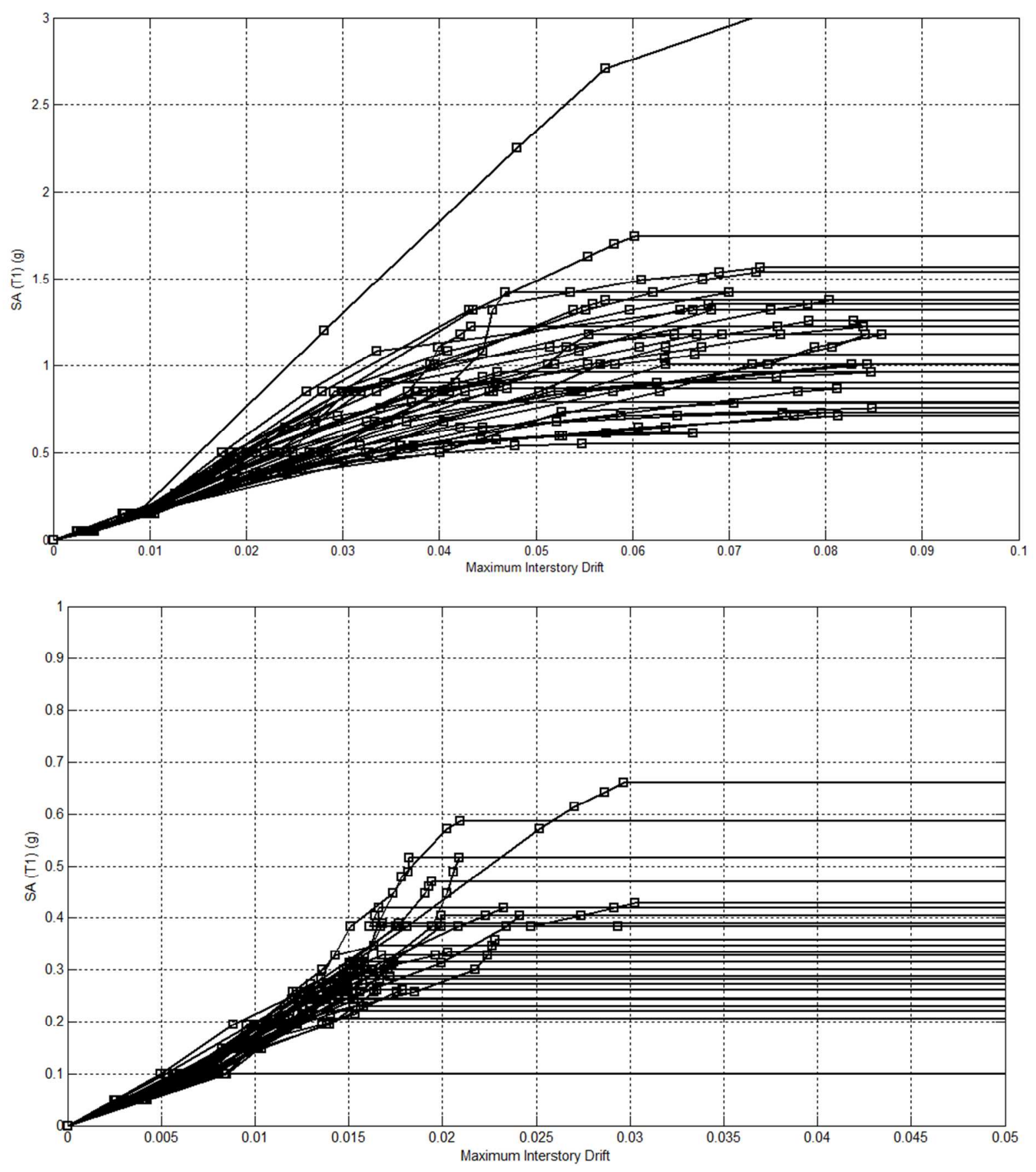


\section{Mean of sample IDA curves}

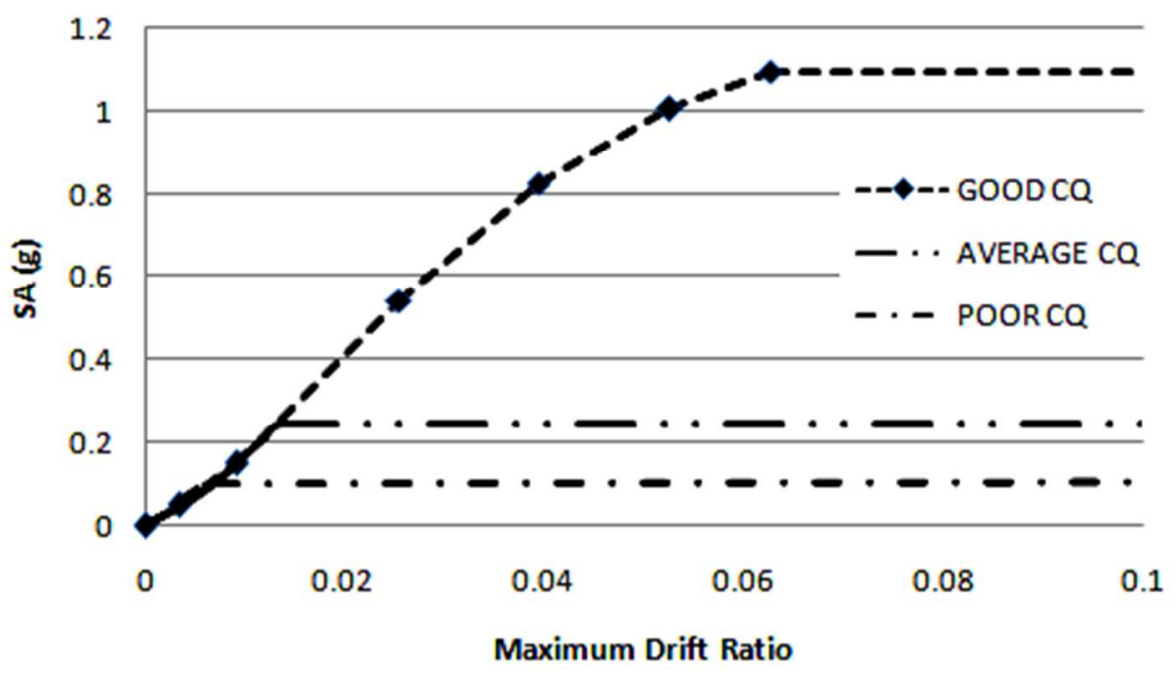



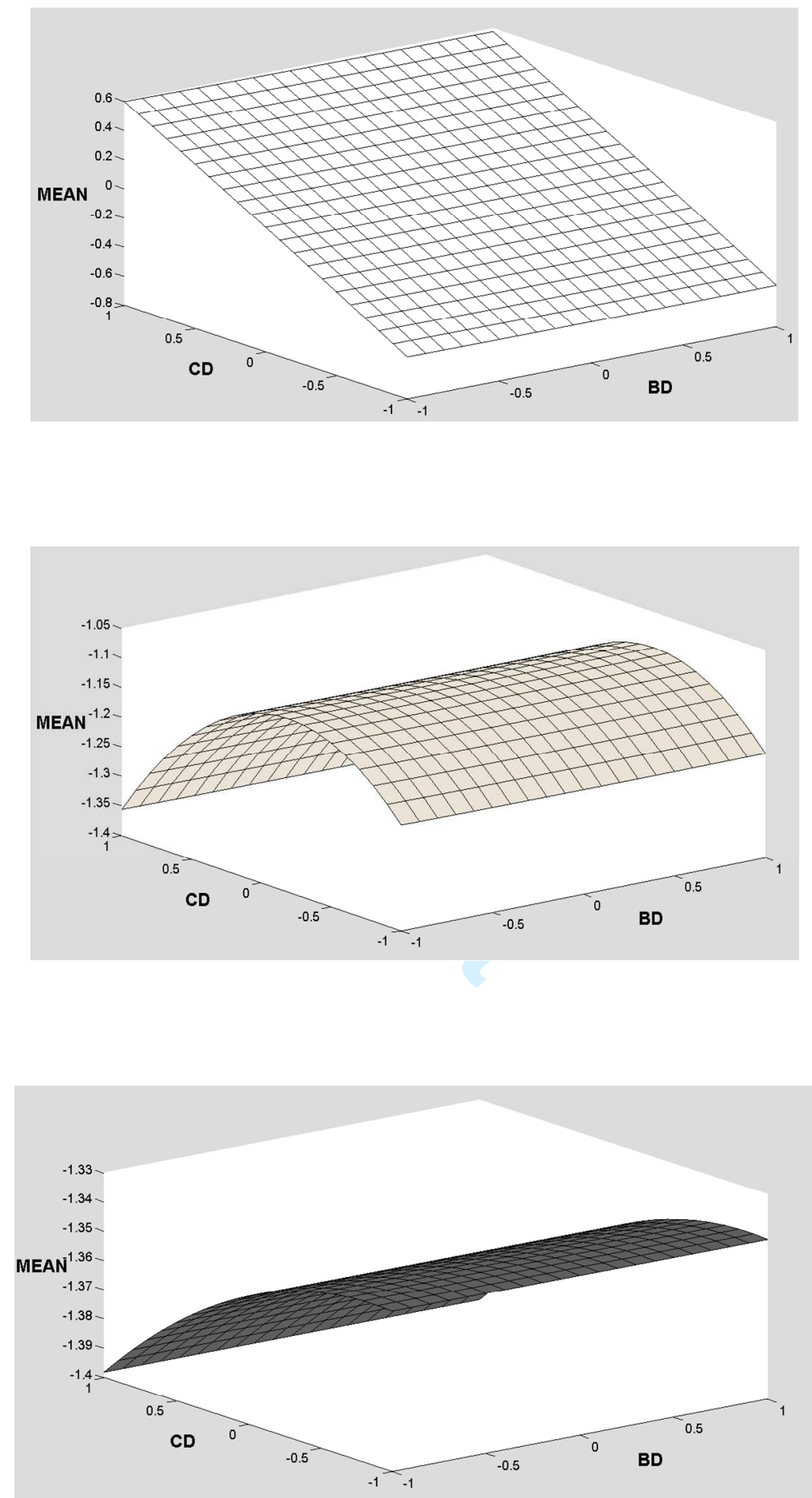

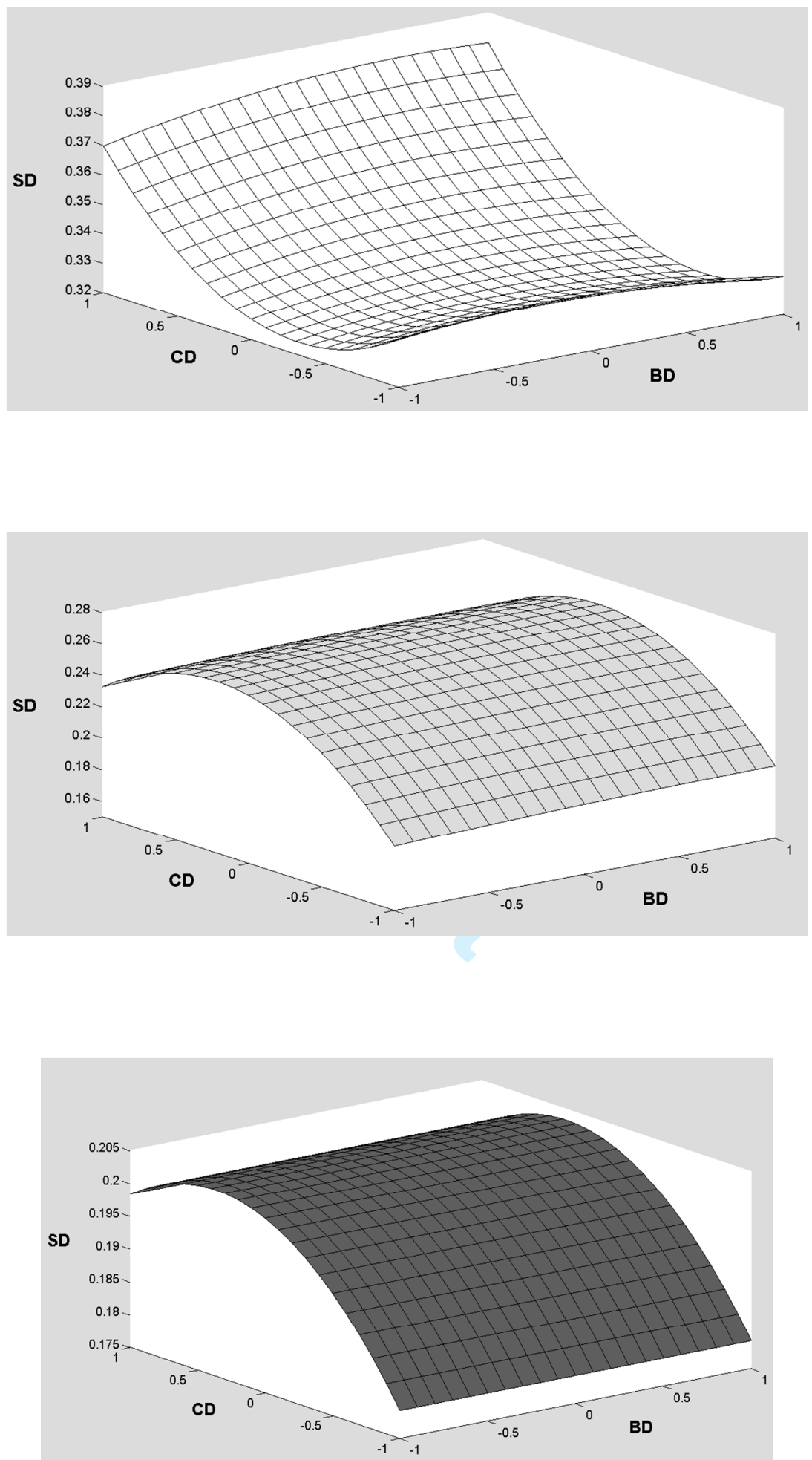


\section{Collapse fragility curves}

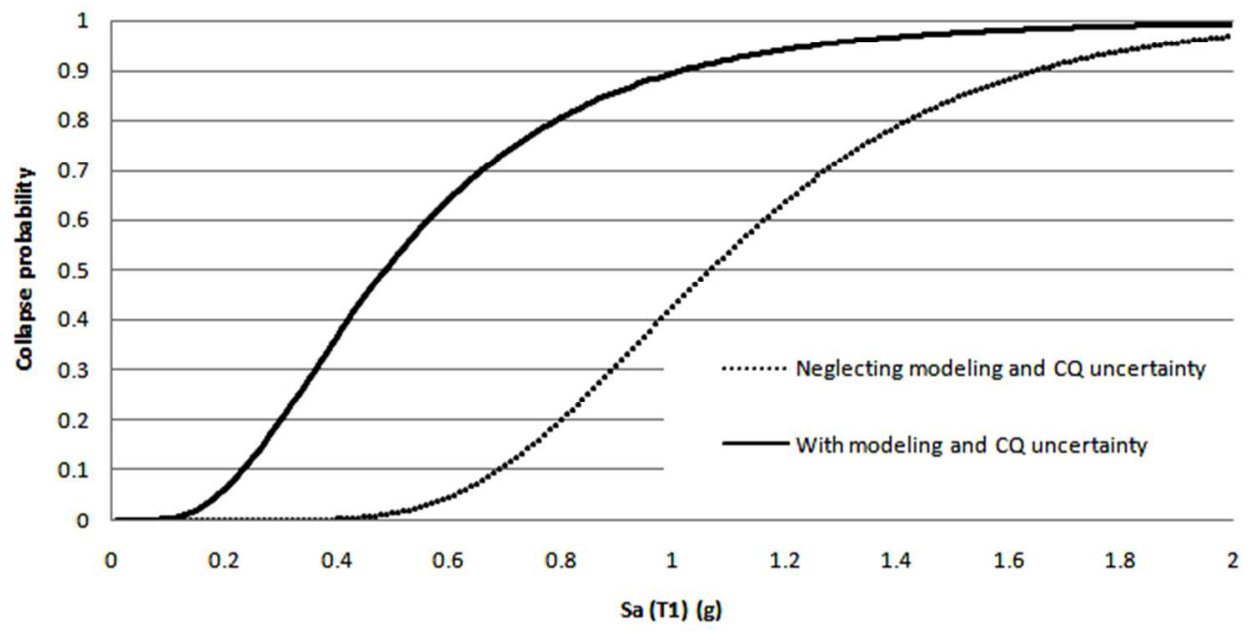




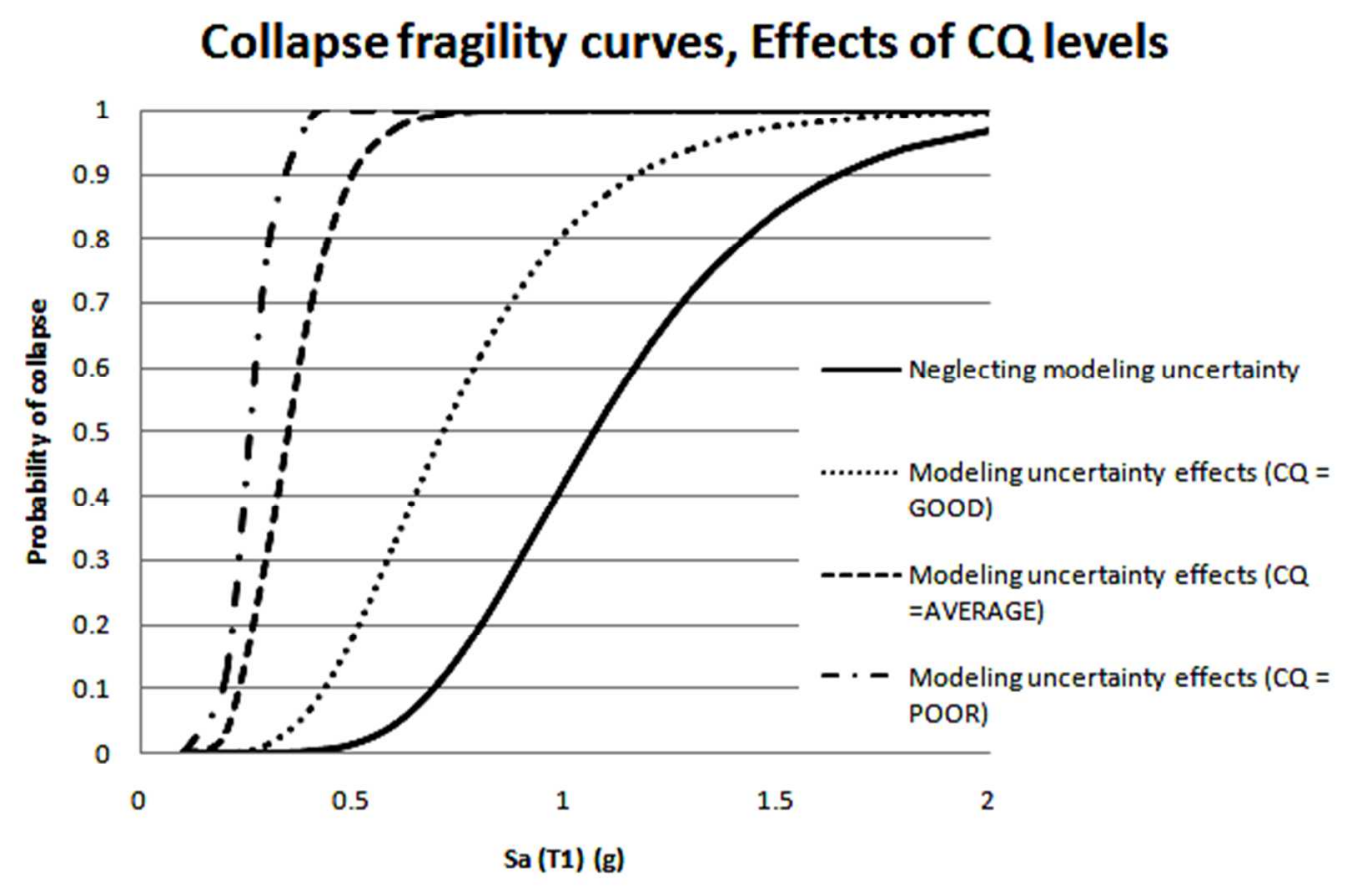




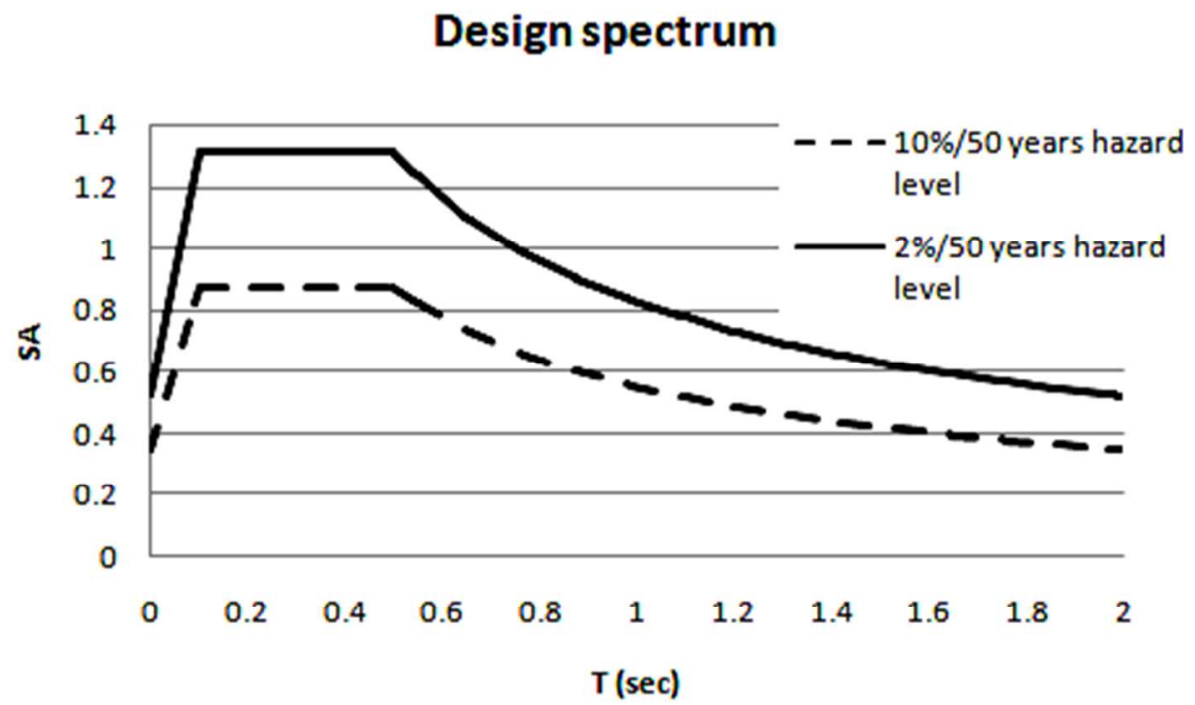

https://mc06.manuscriptcentral.com/cjce-pubs 